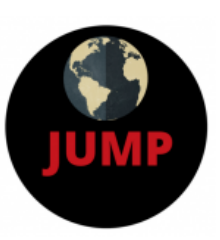

ISSN: 2574-3465 Print/ ISSN: 2574-3481 Online

Volume 4, Issue 1 (2020), pp. 94-100

(C) Journal of Underrepresented and Minority Progress

http://ojed.org/jump

\title{
Faculty Incivility Toward Graduate Students: Voices of Two African American Women
}

\author{
S. Renée Jones \\ Middle Tennessee State University, United States \\ Mattyna L. Stephens \\ Texas State University, United States
}

\begin{abstract}
Student workers are placed at a disadvantage as they have little social power, making them vulnerable to maltreatment by those with higher social power such as supervisors and other faculty members. There is little research that documents incidences of incivility toward student workers. In this study, we delineated the experiences of two African American women who encountered faculty incivility while serving in the role of graduate student worker. The related literature offers insight into the existence of incivility, including the prevalence of workplace incivility, incivility in higher education, social identities, and personal accounts. We offered the Student Worker Support model that can serve as a reference for adult educators as they encounter, supervise, or instruct student workers.
\end{abstract}

Keywords: African American women, incivility, student workers, student worker support model 


\section{INTRODUCTION}

Research related to negative workplace behavior can be traced as far back as the 1970s (Brodsky, 1976). The steady increase in workplace incivility as the nature of work changed caused researchers to focus more intently on the phenomenon. Throughout the research, several constructs have been codified as negative workplace behavior, including workplace aggression, insidious workplace behavior, emotional abuse, incivility, tyranny, workplace harassment or violence, bullying, counterproductive behavior, mobbing (i.e., a group singling out an individual to gang up on to eliminate them from the group), and desk rage (i.e., negative emotional outbursts), to name a few (Björkqvist et al., 1994; Greenberg, 2010; Tigrel \& Kokalan, 2009). Civility involves tolerance and consideration among individuals. According to Putnam (2000), there seems to have been a decline in civility as incivility has become common practice among individuals within the workplace. Incivility is an issue in many organizations, higher education being no exception (Dentith et al., 2014).

The existing literature demarcates workplace incivility within the corporate sector, as well as within academia from the perspectives of faculty and students. However, there is little research that documents incidences of incivility toward student workers. We designed this research to fill this gap by sharing the experiences of two African American female graduate students who were the recipients of funding to support their academic endeavors (e.g., graduate research assistantship [GRA], teaching assistantship [TA], doctoral research assistantship [DRA]) and were the targets of workplace incivility in academia. The research addressed the following questions:

1. How do graduate students perceive faculty incivility and power dynamics in higher education?

2. In what ways does faculty incivility affect graduate students?

The article is organized as follows: (a) pervasiveness of workplace incivility, (b) incivility in higher education, (c) our social identities and workplace incivility, (d) personal accounts, (e) Student Worker Support Model, and (f) conclusion.

\section{Pervasiveness of Workplace Incivility}

Workplace incivility can be identified as behaviors displayed in the 
workplace that violate norms for mutual respect, including "interrupting colleagues, addressing others in an inappropriate manner, and making jokes at another's expense" (Miner \& Cortina, 2015, p. 2). There have been several qualitative inquiries that focused primarily on the suffering endured by targets as a result of workplace hostilities. Findings from one report indicated that of the 401 respondents, over $60 \%$ admitted to being on the receiving end of workplace aggression at some point in their careers (Hollis, 2015). Some researchers have examined the fiscal risks of bullying within organizations (Fritz, 2014), with results indicating how such interferences can cause a disruption in the productivity of targeted employees and ultimately lead to a decline in profits for an organization if the destructive behavior is not addressed (Hollis, 2015). Other researchers explored the effects of workplace aggressions on the health and wellness of employees whether directly or indirectly affected. Persistent abusive behaviors can have increasing physiological and psychological issues for the targeted person (Chen, 2016). These individuals incorporate strategies for avoiding bullies into their daily work routines, though this practice can be emotionally exhausting. Usually, employees who experience such demoralizing behaviors find themselves powerless and unable to take steps to rectify the problem (Chen, 2016).

Typically, women are the target population for any incivilities and minority women are abused at a disproportionately higher rate in the workplace (Frey-Knepp, 2012). Interestingly, acts of incivility are often committed by other women. Nami and Nami (2009) discovered that $71 \%$ of the women in their study experienced maltreatment from other women, whereas only $47 \%$ mentioned incivilities committed by men. Though men commit egregious acts toward women in the workplace, when the outrage is delivered by another woman, the blow is much more striking as women are often viewed as allies and not enemies (Khazan, 2017). However, when women, and particularly minority women, are targeted by both men and women, the incivility can be viewed as a manifestation of racial and gender biases (Johnson-Bailey, 2015).

When employees witness incivilities toward female colleagues, it affects their physical and emotional health along with their job satisfaction, especially if they witness multiple episodes of incivility (Miner-Rubino \& Cortina, 2007). This over exposure can become intolerable, resulting in separation from the organization. As much of the literature surrounding incivility or workplace aggression has been contextualized in nonacademic settings, more research on incivility in academe is warranted (Hollis, 2017). 


\section{Incivility in Higher Education}

Westhue (2008) reported that higher education is fraught with employers committing various acts of incivility. Results of a study conducted by Hollis (2015) showed incivility was more prevalent in academia than the general workforce at $63 \%$ versus $37 \%$, respectively. Some authors would agree academe is a ripe area for the growth of workplace incivility (Faria et al., 2012). Occurrences of incivility in academe are largely related to the demands of networking and social capital building, pressures associated with tenure, and the need to maintain relationships. Many assume that only hierarchical power or vertical aggression are at play. However, Lester (2009) stated incivility can exist among colleagues and hostility can manifest both horizontally and vertically within higher education.

For the past two decades, researchers within the United States and abroad have conducted empirical studies of workplace incivility within the professoriate or academic setting (Hollis, 2015; Keashly \& Neuman, 2013). Keashly and Neuman (2013) indicated, "Academics have paid relatively little attention to bullying in their institutions" (p. 48). Some researchers identified occurrences of incivility among faculty members (faculty on faculty; Sedivy-Benton et al., 2014), which supported the notion that faculty were more likely to view their colleagues as bullies (63.4\%), whereas supervisors were identified as bullies by frontline staff (52.9\%; Keashly \& Neuman, 2013). Although some authors would agree that bullying is a problem overall, there is insufficient literature exploring such a complex topic (Hollis 2015, 2017; Keashly \& Neuman, 2013), and, as a result, researchers have made a call to action to further explore the phenomenon with more rigor (Keashly \& Neuman, 2013). As students and student workers are increasingly affected by workplace incivilities, leaders in adult and higher education may be called upon to offer strategies to support learners who are serving in vulnerable working domains. We offer our stories and recommendations here in an effort to answer the call.

\section{Our Social Identities and Workplace Incivility}

In this study, we delineated our experiences as two African American women who were targets of faculty workplace incivility in academia while serving in the role of student worker. In fulling our academic goals, we found it necessary to procure funding, leading us to become employed by our departments as a GRA, DRA, or TA. Our social identities were female, African American, and student worker. Acknowledging these intersectionalities helped inform how we 
contextualized our experiences. These personal accounts are our perceived recollections of events during that time.

\section{Personal Accounts}

Admittedly, we experienced some trepidation when deciding to disclose our experiences but recognized the forces of power embedded in our anxiety would only serve to prevent our stories from being told. As such, we rejected these feelings of bondage to help shed light on how Black women face challenges within the labor force and the academy that men of color, or White women, seldom experience (Miner \& Cortina, 2015). By critically examining and sharing our accounts, it was our hope that individuals will learn to name such behaviors and navigate systems perpetuating workplace incivility.

\section{Narrative 1: "How dare I ask a question?"}

When I began pursuing my doctorate, I attempted to situate my finances so I could endure the financial sacrifice. Although I had been working in higher education for many years, it had been over 17 years since I had been enrolled as a student. I believed I was mentally prepared to start the doctoral journey. After all, higher education was not new to me, and I had successfully completed bachelor's and master's degrees under less than optimal conditions. However, during my first year I wondered if pursuing doctoral studies was a mistake.

I felt fortunate to be awarded a doctoral research assistant (DRA) position within my program, as I had left my full-time job to devote most of my time toward the pursuit of a doctorate. I spent my first semester as a doctoral assistant quietly learning the culture of the institution, the department, the academic program, and the expectations of the faculty member for whom I worked. During my second semester in the doctoral program, I noticed that although the program was marketed for working adults, faculty often failed to consider the varied responsibilities of the adult students. My questioning of these practices was met with resistance and at times, masked hostility.

On one such occasion, I shared with one of the co-professors of my class that it would have been helpful to students in general to know about a required text for the class in advance. I was told by the professor that I should not be having this conversation with just one of the professors of the class because the class was team taught. I was instructed to schedule a meeting with both professors to discuss my concerns. After speaking with the professor, I decided no additional discussion of the issue was 
warranted. Unfortunately, the professor had a different perspective. I received an email summons for a meeting with both professors of the class on a date determined by them. Although I did not want to meet with either professor, I attended because I depended on the money I received from my doctoral assistantship and believed refusing to meet with them would yield adverse consequences, especially given that one of the professors held another leadership role in the department.

I arrived for the scheduled meeting as requested. Once seated, the professors waited for me to start the conversation. Because I did not request the meeting, I remained silent. The professor who initiated the meeting asked me what I wanted to share. I explained to both instructors that I had not asked for the meeting because I was finished with this topic after my discussion with the professor during class, and that I was in attendance at their "request." Then, they requested I share the concerns I had verbalized during the initial class meeting. After sharing my concerns about the inaccessibility of information, the other professor (the one absent during the initial interaction) launched an attack. Among other things, I was told it was disrespectful to ask for course information in advance. Of course, I was operating under the assumption that, as marketed, the program was geared toward working adults. Because working adults can have many competing obligations, having access to course information in advance could help promote academic success (Ross-Gordon et al., 2017). I left the meeting feeling the professors wanted to make sure I knew who was in charge. How dare I, a lowly doctoral student, question their practices? After meeting with both professors, I thought this should have been the end of the discussion. However, less than 24 hours after the meeting, I received an email from the professor who initiated the meeting. She indicated that she believed there was still tension between us. Again, I informed the professor that I did not request the meeting and had moved on from the issue after I initially shared my concerns during class. Unfortunately, this would not be the last time I would be called to a meeting with faculty.

As a DRA, I was expected to engage in scholarly activity, so I began presenting at professional conferences during my second term in the doctoral program. During my third semester, one of my presentation proposals was accepted at an international conference. I was beyond excited about representing my program, college, and university on an international scale. Although presenting at conferences was an expectation of the DRA position, I was penalized for being absent from class by another professor after attending this international conference. This punitive action negatively affected my final grade. I shared this situation 
with another doctoral student and was told I could file a grade appeal or grievance. However, she reminded me that I would need to be prepared for the possible fallout, given I was working for my program as a DRA. If I had not been dependent on the funding to finance my doctoral studies and fund my living expenses, I would have filed a grievance.

Though I did not file a grievance, I did share with the professor my disappointment in the experience. I discovered that voicing my concerns in contrast to what the professors in my department professed to believe, inevitably resulted in some sort of punitive action. So, again, I was summoned to a meeting to discuss my concerns about the punitive response to my international travel. During this meeting, the professor in question indicated that if I failed to behave with what is termed as political politeness, the program's leaders would be forced to consider alternatives. I considered this response a veiled threat to my assistantship.

As my encounters with the faculty in my program demonstrated, student workers exercising their right to express concerns does not come without risks. Using student assistants' dependence on program funding to suppress their rights is a case of faculty incivility. Students must be allowed to exercise due process without fearing retaliation from faculty.

\section{Narrative 2: A TA's Worst Nightmare}

As a graduate of a historically black college or university (HBCU), I was immersed in a culture of care and compassion during my tenure. There was an abundance of exchanges of micro and macro compassions operating both vertically (i.e., hierarchical power and students) and horizontally (i.e., student to student). Undoubtedly, there was an occasional reprimand handed down by the Residential Advisor or Dorm Director for a minor violation. Regularly, professors emphasized the importance of completing assignments promptly and demanded optimal performance from students. On occasion, the campus police would issue a ticket for parking in the spaces surrounding a particular campus building. Interestingly, and more often than not, the admonishments were given and received in the spirit of love.

I decided to pursue a master's degree at a large, predominately White institution. To complete my studies, I needed some financial backing, so I accepted a TA position that offered the financial support necessary to endure the cost of my education. Securing financial resources made the admittance all the more inviting. To welcome the newly accepted students, Sylvia (pseudonym), a White woman who supervised the TAs, hosted a dinner at her home. When it was time to eat, she begrudgingly 
served me and emphatically rolled her eyes. Sylvia's behavior marked the beginning of what would be a stressful semester. Throughout this narrative, I will refer to my experiences with Sylvia as rounds.

Round 1. As part of the requirements for my TA position, I was responsible for teaching some courses within the department. I scheduled a meeting with Sylvia to discuss the intricacies of my job. During our initial meeting, she seemed annoyed by my presence. She hastily read through documents requiring further explanation. Each time I attempted to ask a question, she would let out a sigh, seemingly frustrated by my inquiries. As a result, I decided to steer the meeting in the direction of closure rather than continue the interaction. Once the meeting ended, Sylvia shoved the papers in my direction, quickly stood up, issued a forced grin, and departed. I was left speechless.

Round 2. While teaching, I periodically borrowed equipment from the technology department to video record the sessions. I was advised by the supervisor of the technology department to leave the equipment in a designated area. Indeed, I responded to the request. The following day, Sylvia stormed into my class and abrasively reprimanded me for leaving the equipment in the designated area. I attempted to explain to her that I was advised by the supervisor where to place the equipment. She insisted that I was not given those directives and made the claim that she had spoken to the supervisor. While my initial thought was to take her to task, I did not let my emotions get the better of me. I also did not want to risk losing the funding that supported my education.

Meanwhile, some of the onlookers were in awe of Sylvia's behavior. One student referred to Sylvia as a racist and revealed that these outbursts were not unusual. Lamentingly, the eruptions and abrasive comments directed toward me became more pervasive.

Round 3. Sylvia became stealthier with her incivilities. Seemingly, she began to encourage others from the department to take part in these episodes. For example, she encouraged another student to inquire as to whether I had driven to a mandatory professional development event. In response, I wittingly quipped, "No." More importantly, my response was loud enough for Sylvia to hear. Indeed, I had not driven to the engagement. Instead, I used public transportation (i.e., the city bus). To add, I collected signatures from the facilitators as proof that I was in attendance.

A few days later, Sylvia called my home, and abrasively reprimanded me for failing to attend the professional development engagement. She proceeded to tell me she had proof of my absence. To counter her claim, I informed her of the signatures that I collected and 
asked if she wanted to view them. She paused, expelled a loud sigh, and hung up the phone.

Sylvia displayed such behaviors as falsifying information, abuse of power, and hostile or unethical communication. Although Sylvia's maltreatment was unpleasant, at the time, I was unable to attach a specific name to the behaviors. In the literature, Clark (2017) referred to such acts as faculty incivility. In response to these acts, I began to avoid Sylvia. At times, I wanted to confront her about the maltreatment but decided against confrontation for two reasons. First, for fear it could escalate. Second, to counter the negative stereotypes (e.g., defensive, attitudinal, or confrontational) concomitant to Black women. Eventually, I became withdrawn and avoided participating in departmental activities. Although I wanted to share the information with someone, I was unaware of how this would affect my education. Fortunately, Sylvia's uncivil behaviors did not result in my leaving the program. However, they [behaviors] added another layer to the already existing stressors of being the only African American in the master's program, attending a large predominately White institution, and meeting the demands of the TA position and coursework.

In time, I shared my experiences with one of the members of the department. She listened carefully to my concerns, took copious notes, and assured me my divulgence was not in vain. More importantly, she kept her word. Later that week, I received a call from another person who served in a leadership role within the department. I provided him with a detailed description of the occurrences. During the next meeting, he addressed the atrocities. At first, Sylvia denied the accusations. As the conversation continued, she trivialized the brutal attacks and reluctantly apologized. Based on these experiences, I learned the importance of being vocal about incivilities. I also learned to remain balanced to counter the stereotypes often associated with Black women.

\section{Knowing Our Place}

Those in the field of adult education advocate for social justice, inquiry, and reflective practice and must be purposeful in maintaining the landscape of the field (Ross-Gordon et al., 2017). When we were immersed in our personal tragedies, it was important for us to maintain the financial support necessary to successfully complete our programs of study. Because of this, we had to know our place. In this space of suffering, we were members of marginalized groups (i.e., women, African American, student workers) and were targeted by faculty, all while trying to meet the responsibilities of our jobs and coursework. 
As students in very complex and vulnerable situations, we were forced to learn strategies for avoidance (i.e., escaping the jaws of the aggressor whenever possible), silence (i.e., suppressing any verbal or nonverbal communication that could be misinterpreted), and persistence (i.e., enduring every attack the aggressor launched) to ensure survival. In this case, survival is a code name for coping. According to Lapina (2018), when adults are unable to manage stressful encounters, they employ coping strategies of any form to ameliorate the situation. Failing to do so can affect their emotional well-being as well as their learning and educational outcomes. Albeit exhausting, it was important for us to stay two steps ahead of our opponents (i.e., faculty). Since our experiences, we have become faculty of adult education. Our experiences informed our decision to create a model in support of student workers.

\section{Student Worker Support Model}

We developed a self-reflective model titled Student Worker Support (SWS model) that faculty of adult education can use as a frame of reference as they continue to supervise student workers directly or indirectly. The components of the model include maintaining positionality identifying the discomfort, creating opportunities for building capacities, controlling emotions, and engaging in reflective practice.

\section{Maintaining Positionality}

As adult education faculty, we understand the discipline's political-philosophical underpinnings and power dynamics when endeavoring to build and sustain programming offering financial resources supporting students' long-term academic goals. Student workers are placed at a disadvantage as they are less socially powerful, making them vulnerable to maltreatment by those with higher social power such as supervisors and other faculty members (Miner \& Eischeid, 2012). Therefore, it is important for faculty to critically examine and identify their multiple positionalities within academe, particularly faculty to student, and more deeply explore the power dynamics of this relationship to use their positionalities effectively and not abusively. The inappropriate use of power has long-term effects in this faculty to student interaction (Robertson, 2016).

\section{Identifying the Discomfort}

Women, particularly Black women, who are adult learners have 
membership in myriad marginalized groups (Alfred, 2007). Black women are not characterized by a single element; there is an intersection of marginalizing characteristics leading to the need to include and support people differently. In our experiences, we realized faculty often experience trepidation during their interactions with African American women. In response to this discomfort, faculty sometimes prematurely assume a defensive stance prior to engaging in verbal or nonverbal interactions with Black women. Though lamentable, these preconceived notions of Black women are more impactful and fearful than the actual representation (Collins \& Blige, 2016). Therefore, it is important for adult education faculty to critically examine their level of discomfort to determine its place of origin and work to reconcile any deficit ideologies that may fuel incivility toward students. Adult education faculty may also look to other faculty within and across departments to access knowledge and skills related to cultural sensitivity to help rethink their perceptions of African American women.

\section{Creating Opportunities for Building Capacities}

Dentith et al. (2015) encouraged adult educators to keep the field of adult education vibrant and healthy. To do so, faculty may need to recruit students with innovative ideas for research and create more unique opportunities packaged in TA, GRA, DRA, and similar positions within and across departments to support student learning and development. As faculty supervise student workers, it is important to build students' capacities in the areas of research, writing, and teaching, rather than creating a climate of incivility. Although these positions are sometimes designed to decrease the already stressed workload of faculty, by infusing research, teaching, and writing opportunities into students' job responsibilities, the applications of such skills can help restore the field's vibrancy.

\section{Controlling Emotions}

Graduate student workers serve in vulnerable roles; therefore, it is the responsibility of the guiding faculty supervisor to use authority appropriately (Robertson, 2016). Adult education faculty must reflect on a time when a student worker posed a question regarding policies, methods of practice or of general inquiry within the classroom or within the work environment. Did you feel challenged? How did you respond? Did the anger lead to vindication manifesting in acts of incivility indicating the student's assistantship would be placed at risk? Inquiry of any kind should 
not be viewed as a threat to the learning process. Rather, for adults, when inquiry is embedded in instruction, epistemological positioning is altered and learning becomes an active process (Morris, 2018).

When the exchanges between faculty and student workers have the propensity to escalate into forms of incivility, it is important for faculty to manage their emotions. To manage emotions, it was recommended that faculty engage in mindfulness or "the practice of focusing on breathing" (Lapina, 2018, p. 137). Participants can engage in breathing exercises starting with 10- to 15-minute intervals to manage stress-related activities and promote a boost in clarity of thought. Faculty can practice these exercises uninterrupted prior to interacting with students.

\section{Engaging in Reflective Practice}

In adherence to the age-old maxim, "practice makes perfect," it is helpful for faculty to engage in reflective practice for the purpose of selfawareness. Reflective practice goes beyond thoughtful practice. Rather, it problematizes many situations of professional performance so they can become potential learning situations so practitioners can continue to learn and develop (Jarvis, 1992). With this in mind, faculty can situate themselves in the context of their experiences in multiple ways to confront as well as understand contradicting elements within practice while identifying both actual and desirable performance to engage more effectively with student workers. Baumgartner (2001) asserted that whether gradual or sudden, this transformational process can alter how people, and in this case faculty, see themselves in their existence.

The SWS model can be implemented in a cyclical process where each element builds upon the next. The elements within the structure can be used separately or in conjunction with other elements dependent upon the format of the interaction. For the application of the framework to be most effective, adult educators must be proactive rather than reactive. This means faculty must be deliberate about learning the model and each of its parts prior to student worker interaction. It is also important for faculty to refer to the model often for appropriate application of the elements embedded in the framework.

\section{CONCLUSION}

We experienced incivilities in academe from faculty whose social power at the time seemed to trump ours. As securing financial resources was necessary for completing our programs, we held on to our dream and endured the abuse. Faculty who supervise student workers are looked upon 
as mentors and sponsors. Yet, some have used their power and positionality to promote incivility within the workplace. We hope readers will find our recommendations useful in supporting both faculty and adult learners. It is important for faculty to put into practice the aforementioned components of the SWS model to avoid contributing to the culture of incivility within the academy.

As with any research, there are limitations to the present study. Given the small sample size, we do not suggest the outcomes can be generalizable. Though we believe our stories add fresh insights, we hope more adult educators will continue to investigate workplace incivility and share their experiences and best practices. We also suggest more research of the experiences of adult education faculty experiencing mobbing by student cohorts.

\section{REFERENCES}

Alfred, M. (2007). Welfare reform and Black women's economic development. Adult Education Quarterly, 57, 293-311. doi:10.1177/0741713607302685

Baumgartner, L. M. (2001). An update on transformational learning. New Directions for Adult and Continuing Education, 89, 15-24. doi:10.1002/ace.4

Björkqvist, K., Österman, K., \& Hjelt-Bäck, M. (1994). Aggression among university employees. Aggressive Behavior, 20, 173-184. doi:10.1002/10982337(1994)20:3<173::aid-ab2480200304>3.0.co;2-d

Brodsky, C. M. (1976). The harassed worker. Lexington Books.

Chen, D. D. (2016). Stress management and preventions: Applications for daily life. Routledge.

Clark, C. M. (2017). An evidence-based approach to integrate civility, professionalism, and ethical practice into nursing curricula. Nurse Educator, 42, 120-126. doi:10.1097/nne.0000000000000331

Collins, P. H., \& Blige, S. (2016). Intersectionality. Polity Press.

Dentith, A. M, Wright, R. R., \& Coryell, J. (2014). Those mean girls and their friends: Bullying and mob rule in academy. Adult Learning Journal, 26(1), 28-34.

Faria, J. R., Mixon, F. G., \& Salter, S. P. (2012). An economic model of workplace mobbing in academe. Economics of Education Review, 31(5), 720-726. doi:10.1016/j.econedurev.2012.04.004

Frey-Knepp, K. (2012). Understanding student and faculty incivility in higher education. The Journal of Effective Teaching, 12(1), 32-45.

Fritz, J. (2014). Organizational misbehavior. In J. C. Lipinski \& M. Laura (Eds.), Bullying in the workplace: Causes, symptoms, and remedies (pp. 3-16). Routledge.

Greenberg, J. (Ed.). (2010). Insidious workplace behavior. Routledge Academic.

Hollis, L. (2015). Bully university? The cost of workplace bullying and employee engagement in American higher education. Sage Open, 5(2), 1-11. doi: $10.1177 / 2158244015589997$ 
Hollis, L. (2017). Evasive actions: The gendered cycle of stress and coping for those enduring workplaces bullying in American higher education. Advances in Social Sciences Research Journal, 4(7), 59-68. doi:10.14738/assrj.47.2993

Jarvis, P. (1992). Reflective practice and nursing. Nurse Education Today, 12, 174 181.

Johnson-Bailey, J. (2015). Academic incivility and bullying as a gendered and racialized phenomenon, Adult Learning, 26, 42-47. doi:10.1177/1045159514558414

Keashly, L., \& Neuman, J. H. (2013). Bullying in higher education: What current research, theorizing, and practice tell us. In J. Lester (Ed.), Workplace bullying in higher education (pp. 1-22). Routledge.

Khazan, O. (2017, September). Why do women bully each other at work? The Atlantic. Retrieved from

https://www.theatlantic.com/magazine/archive/2017/09/the-queen-bee-inthe-corner-office/534213/

Lapina, A. (2018). Facilitating coping through reflective learning in adult education: A review of the reciprocal relationship between coping and learning. Adult Learning, 29, 131-140. doi:10.1177/1045159518776126

Lester, J. (2009). Not your child's playground. Workplace bullying among community college faculty. Community College Journal of Research and Practice, 33, 444-462. doi:10.1080/10668920902728394

Miner, K., \& Cortina, L. M. (2015). Observed workplace incivility toward women, perceptions of interpersonal injustice, and observer occupational well-being: Differential effects for gender of the observer. Frontiers in Psychology, 7, Article 482. doi:10.3389/fpsyg.2016.00482

Miner, K., \& Eischeid, A. (2012). Observing incivility toward coworkers and negative emotions: Do gender of the target and observer matter? Sex Roles: A Journal of Research, 66, 492-505. doi:10.1007/s11199-011-0108-0

Miner-Rubino, K., \& Cortina, L. M. (2007). Beyond targets: Consequences of vicarious exposure to misogyny at work. Journal of Applied Psychology, 92, 1254-1269. doi:10.1037/0021-9010.92.5.1254

Morris, H. T. (2018). Adapt through self-directed learning to meet the challenges of our ever-changing world. Adult Learning Journal, 30(2), 56-66.

Nami, G., \& Nami, R. (2009). The bully at work: What you can do to stop the hurt and reclaim your dignity at work. Sourcebook.

Putnam, R. (2000). Bowling alone: The collapse and revival of American community. Simon \& Schuster.

Robertson, S. (2016). Student-workers and tourist-workers as urban labour: Temporalities and identities in the Australian cosmopolitan city. Journal of Ethnic and Migration Studies, 42, 2272-2288. doi:10.1080/1369183X.2016.1205808

Ross-Gordon, J., Rose, A., \& Kasworm, C. E. (2017). Foundations of adult and continuing education. Jossey-Bass.

Sedivy-Benton, A., Stroheschen, G., Cavazon, N., \& Boden-McGill, C. (2014). Good ol' boys, mean girls, and tyrants: A phenomenological study of the lived experiences and survival strategies of bullied women adult educators. Adult Learning, 26, 35-41. doi:10.1177/1045159514558411 
Tigrel, E. Y., \& Kokalan, O. (2009). Academic mobbing in Turkey. International Journal of Behavioral, Cognitive, Educational and Psychological Science, $1,91-99$.

Westhue, K. (2008, October). The complexity of academic bullying. The Chronicle of Higher Education, p. B23.

S. Renée Jones, Ph.D., is an Assistant Professor in the University Studies Department at Middle Tennessee State University. Her major research interests lie in the area of equity and access in higher education. Email: renee.jones@mtsu.edu

Mattyna L. Stephens, Ph.D., is a Lecturer at Texas State University in the Department of Counseling, Leadership, Adult Education, and School Psychology. Her major research interests lie in the areas of women's studies and distance education. Email: mls351@txstate.edu 